\title{
Intestinal Parasitic Infections and Eosinophilia in an Human Immunedeficiency Virus Positive Population in Honduras
}

\author{
Rina G Kaminsky/ ${ }^{+}$, Ramón J Soto*, Adriana Campa, Marianna K Baum**
}

\begin{abstract}
Dirección de Investigación Científica *Facultad de Ciencias Médicas, Universidad Nacional Autónoma de Honduras y Hospital-Escuela, Casilla Postal 1587, Tegucigalpa, Honduras **College of Health and Urban Affairs, Florida International University, Florida, US
\end{abstract}

The occurrence of intestinal parasites, their regional distribution and their relations to eosinophilia were studied in 133 human immunodeficiency virus (HIV) positive individuals from Honduras. After signing an informed consent, participants answered a socio-demographic and risk factor questionnaire, a complete physical examination, medical history, and a series of laboratory tests. All participants were HIV positive but not acquired immunodeficiency syndrome positive. Of them, $67 \%$ were co-infected with pathogen and non pathogen parasites. Overall occurrence of nematodes was: $44.3 \%$ for Trichuris trichiura, 24\% for Ascaris lumbricoides, $12 \%$ for Hookworm and 7.5\% for Strongyloides stercoralis. No cases of Giardia lamblia, acute amebiasis or cryptosporidiasis were diagnosed. Mean eosinophil percents for participants were consistently and significantly higher in infected than in non infected individuals: $22 \%$ for Hookworm vs $7.2 \%$ ( $p<0.001$ ), $11 \%$ for Trichuris compared to $5.2 \%(p<0.001), 13.2 \%$ compared to $7.5 \%$ for $\mathrm{S}$. stercoralis $(p<0.05)$, and $12 \%$ compared to $6 \%$ for Ascaris cases $(p<0.05)$. Helminths and non pathogenic protozoa, as single or mixed infections, occurred among the participants. There was a strong correlation between eosinophilia and helminthiasis infections; however, none was identified between CD4 levels and eosinophilia. Because parasitic infections aggravate malnutrition and promote a disbalanced Th2 response in a potentially immuno-compromised host, their effect on HIV disease progression needs further study, mainly in countries were HIV and parasitic infections are highly prevalent.

Key words: eosinophilia - helminth infection - human immunodeficiency virus - intestinal parasites - Honduras

In times when the human immunodeficiency virus (HIV) has caused the largest and the most devastating pandemic in the history of humankind, parasitic infections still remain one of the most prevalent types of infection in the world (Savioli et al. 2002). Many of the populations at high risk for HIV also live in highly endemic areas of intestinal parasitic infections, which are mainly acquired in childhood and remain as chronic infections into adulthood (Bundy et al. 2000). There is mounting evidence that these helminthic infections influence the HIV disease progression by regulating the host immune response, both at the cellular and humoral level, as the result of a strong T helper 2-type cytokine profile (Kalinkowich et al. 1998, Bentwich et al. 1999, Bundy 2000, Borkow et al. 2001, Baum et al. 2003).

Honduras has the highest prevalence of human immunodeficiency virus/acquired immunodeficiency syndrome (HIV/AIDS) in Central America (Soto 1998), and also bears a high burden of parasitic infections (Kaminsky 1996). Both helminthic and protozoan infections are highly prevalent in the country, and parasites such as Strongyloides stercoralis, Ascaris lumbricoides, Trichuris trichiura, and

Financial support: The Fogarty International Center, University of Miami School of Medicine, Universidad Nacional Autónoma de Honduras

${ }^{+}$Corresponding author. Fax: +504-238.2449. E-mail: fundar@cablecolor.hn.

Received 16 March 2004

Accepted 22 September 2004
Hookworms, known to be strongly associated with a Th2 cytokine shift accompanied by eosinophilia, could represent a condition associated with rapid immunocompetence deterioration, as observed empirically in Honduras in those HIV infected individuals. This study shows for the first time in Honduras the epidemiological evidence of a high degree of co-infection with parasitic intestinal helminths associated to eosinophilia and HIV.

Background - In developing countries, it is impossible to ignore the burden of parasitic infections usually categorized as diseases of poverty (Evans \& Jamison 1994). The presence of individuals infected with intestinal parasites in situations of poverty, with deficient sanitary infrastructure, lack of latrines or poor use of them, overcrowding, and soil characteristics favorable for the proliferation of parasites provide conditions for the maintenance and transmission of such infections (Beaver et al. 1985). According to WHO estimates, at least 2 billion people in the world suffer from helminthiasis, and, of those, approximately 300 million suffer associated severe morbidity (Savioli et al. 2002). These infections represent more than $40 \%$ of the disease burden due to all tropical diseases, excluding malaria (Savioli et al. 2002). In many Latin American countries, endemic intestinal parasitosis is persistent and prevalent in people of all ages, specially the soil-transmitted helminths and the protozoa Cryptosporidium parvum, Giardia lamblia, and Entamoeba histolytica, with rates of infection from 10 to $50 \%$ or higher (Botero 1981, Alemán \& Sousa 1991, INDRE 1994). Prevalence data from intestinal parasite surveys in Honduras are scarce, but statistics from hospitals and health clinics show a regional distribution of common intestinal para- 
sites with varying rates for different age groups that range from $45-70 \%$ at the North coast, to $5-8 \%$ in the South (Kaminsky 1996).

The morbidity associated with such infections includes a wide range of abdominal complications, including malnutrition, chronic anemia, and dysenteric syndrome, all of which affect growth, development, and cognitive capacity in children, as well as work productivity in adults (Beaver et al. 1985, Guyatt 2000, Savioli et al. 2002). In many cases, the magnitude of these distortions has been found to be largely proportional to the worm burden (Beaver et al. 1985, Nokes et al. 1992). On the other hand the influence of HIV-1 infection characterized by a Th1 type immune response may decrease interleukine-5 and IgE responses in patients with strongyloidiasis, which usually produces asymptomatic or mild infections, and develop into severe disseminated strongyloidiasis (Porto et al. 2001, Loufty et al. 2002). The emergence of HIV/ AIDS has furthermore heightened the spectrum of opportunistic parasites by enabling more aggressive and disseminated parasitic infections in human such as cryptosporidiasis, isosporiasis, toxoplasmosis and strongyloidiasis (Vomer et al. 1987, Heyworth 1996). Individuals with HIV/AIDS infection experience specific immunologic alterations with newly acquired infections or reactivation of latent ones that can occur despite high titers of circulating antibodies (Vomer et al. 1987, Heyworth 1996).

Approximately $46 \%$ of all AIDS cases reported from Central America are originated in Honduras (Soto 1998). Recent estimates indicate an adult (15 to 49 years old) HIV prevalence of $1.6 \%$ (Soto et al. 2002). Most HIV therapy was at the experimental stage and mostly unavailable for developing countries in 1996, at the time this research was conducted (Wheeler et al. 2001). In countries such as Honduras, with per capita allocation for health care of only a few US\$ per year, anti-retroviral therapies have been beyond the reach of all but a privileged few. Consequently, opportunistic infections appear early and are frequent when patients develop AIDS. A study of the clinical and epidemiological characteristics of the first 100 AIDS patients seen at a tertiary care level hospital in Honduras' capital city, Tegucigalpa, indicated that diarrhea accounted for $71 \%$ of the clinical symptoms; candidiasis for $37 \%$, tuberculosis for $20 \%$, and different intestinal parasitic infections (47\%) of which C. parvum (14\%) and
Isospora belli ( $8 \%$ ) were present and considered markers of an immunocompromised system (Bu et al. 1992).

In countries where both parasitic and HIV infections are highly prevalent, such as in Honduras, the prevention and management of these diseases and their complications are critical. The present study describes the prevalence of intestinal parasitic infections in Honduras in an HIV infected population in five large cities in Honduras, and the associations with eosinophilia, which is considered a marker of a Th2 response.

\section{POPULATION AND METHODOLOGY}

Between March and November 1996, a total of 326 HIV seropositive individuals from all those attending public clinics that belong to the Ministry of Health were deliberatedly recruited for a study by the University of Miami investigating HIV subtypes and human herpesvirus 8 infections (Sosa et al. 1998, Renjifo et al. 1999). Participants represented a cross-sectional sampling of the population and were recruited, when eligible, as they visited the clinic during their routine medical check up. They were enrolled consecutively after signing an informed consent form. Of the 326 participants, 133 (40.8\%) agreed to provide stools for a parasitological examination. Participants with AIDS, intravenous drug users, and hemophiliacs were excluded. The study individuals were recruited from 5 major cities: Tegucigalpa (the capital city), Comayagua, a city in the Central region, San Pedro Sula (the second largest city, at the North coast), and La Ceiba and Tela, also in the Northern region.

A socio-demographic and risk factor questionnaire, a complete physical examination, a focused medical history, and a series of laboratory tests performed in a certified United States laboratory included a complete hemogram, CD4 cell counts, genital specimen cultures, serology tests, HIV-1 ELISA and Western Blot tests. A single stool sample was obtained from each individual for parasitologic diagnosis, collected fresh in a clean plastic vial properly identified and received for processing in Tegucigalpa at the Hospital-Escuela Parasitology Laboratory in the same day. The stool samples were examined by the following methods: a direct smear ( $\pm 2 \mathrm{mg}$ of feces $)$ in physiologic saline solution, a direct smear in Lugol's iodine solution, a Kato thick smear (Katz modification, $41.7 \mathrm{mg}$ feces) to estimate the intensity of soil-transmitted helminths, a modified Baermann method to recover $S$. stercoralis larvae, a for-

TABLE I

Frequency of intestinal parasites in human immunedeficiency virus positive participants in Honduras, by city of origin

\begin{tabular}{|c|c|c|c|c|c|c|c|c|c|}
\hline \multirow{2}{*}{$\begin{array}{l}\text { City and number of } \\
\text { participants }\end{array}$} & \multirow{2}{*}{$\begin{array}{c}\text { Overall } \\
\text { prevalence } \%\end{array}$} & \multicolumn{8}{|c|}{ Species of parasites } \\
\hline & & $T t$ & $A l$ & Hkw & Ss & T. sp & $E h / E d$ & $C c$ & $I b$ \\
\hline Tegucigalpa $(n=46)$ & 58.6 & 36.9 & 26.0 & 8.7 & 6.5 & 2.1 & 4.3 & 8.6 & 0.0 \\
\hline Comayagua $(n=29)$ & 62 & 34.4 & 27.5 & 0 & 10.3 & 0 & 10.3 & 6.8 & 3.4 \\
\hline San Pedro Sula $(n=38)$ & 68.4 & 57.8 & 18.4 & 23.6 & 5.2 & 0 & 5.2 & 5.2 & 0.0 \\
\hline Tela/La Ceiba $(\mathrm{n}=20)$ & 90 & 50.0 & 25.0 & 15.0 & 10.0 & 0 & 15.0 & 5.0 & 0.0 \\
\hline Total $(\mathrm{n}=133)$ & 66.9 & 44.3 & 24.0 & 12.0 & 7.5 & 0.7 & 7.5 & 6.7 & 0.7 \\
\hline $95 \%$ C.I. & $59.2,82.9$ & & & & & & & & \\
\hline
\end{tabular}

Tt: Trichuris trichiura; Al: Ascaris lumbricoides; Hkw: Hookworm; Ss: Strongyloides stercoralis; Eh/Ed: Entamoeba histolytica/E. dispar; Cc: Cyclospora cayetanensis; Ib: Isospora belli; T. sp: Taenia sp. 
malin ethyl-acetate concentration to detect light infections and a modified acid fast stain to identify oocysts of intestinal apicomplexa (Ash \& Orihel 1987, WHO 1994). The species of protozoa were identified by morphological characteristics of the cyst form and/or trophozoites as seen in a Lugol stained direct smear and concentrated sediment. Care was exerted to distinguish the most outstanding features of the five common species of ameba in man (E. histolytica/E. dispar, E. coli, E. hartmanni, Endolimax nana, Iodamoeba buetschlii) using oil immersion objective in a wet Lugol stained smear (Beaver et al. 1985, WHO 1994). E. hartmanni was recognized by tetranucleated cysts measuring less than $10 \mu \mathrm{m}$ in diameter; tetranucleated cysts measuring $10 \mu \mathrm{m}$ or more were categorized as E. histolytica/E. dispar species (Beaver et al. 1985, Diamond \& Clark 1993). Diagnosis was achieved after studying many cyst forms. Zoonotic species or the flagellate Dientamoeba fragilis with no cyst stage, however, may have gone unrecognized.

Identification and quality control for intestinal apicomplexa was provided by including positive samples at the time of staining as well as by oocyst morphology and size. Descriptive and univariate analyses were performed using Epi Info 6, version 6.04b, 1997 (CDC, Atlanta).

\section{RESULTS}

Complete data from the 326 participants have been already published elsewhere (Sosa et al. 1998, Renjifo et al. 1999). For purposes of our study, we present data on the 133 participants. Demographics obtained indicate that $99(74 \%)$ were women and 34 (26\%) were men. The majority were from a low socio-economic status. The mean age was $30.5 \pm 7.6 \mathrm{yrs}$, with a range between 17 and $63 \mathrm{yrs}$ old. Sixty six percent were single and $17 \%$ had common law partners. The rest were widowed $(8 \%)$, married $(8 \%)$ or divorced (1\%). The mean education was $5.0 \pm 3.2$ yrs of school, with a range between 0 to $12 \mathrm{yrs}, 12(9 \%)$ were illiterate and one third had only 3 or less years of education. Housewife (28\%) and commercial sex worker (19\%) were the most frequent stated occupations among the participants.

The majority of our participants (93\%) were asymptomatic. It was mentioned that during the enrolment those individuals with AIDS were excluded since the purpose of the Miami University study was to evaluate HIV positive but asymptomatic persons with an intact immune system. The rest (7\%) had some isolated symptoms not allowing AIDS categorization. None of the participants were receiving antiretroviral therapy.

Among 127 subjects who provided blood samples the following laboratory results were obtained: the median hemoglobin was $13.1 \mathrm{~g} / \mathrm{dl}$ (range 7.3-16.7 g/dl) and the median hematocrit $38.5 \mathrm{vol} \%$ (range $22-49 \mathrm{vol} \%$ ). The median leukocyte count was 6.6 x 103/ $\mu$ (range 2300-16,900/ $\mu 1)$. The median eosinophil count was $8.1 \%$ (range $0.4-$ $43 \%$ ), above the acceptable range. The median of CD4+ cell count was 357 cell $/ \mathrm{mm}^{3}$, with a range between 32-890; four individuals had counts of 1166, 1218, 1244, and 1626. Twenty three point six percent of the participants had CD4 $<200$ cells $/ \mathrm{mm}^{3}$; by stratifying the immunological marker with eosinophilia, half of the individuals with
$<200$ CD4 cells had eosinophilia with (7 of 30) or without ( 8 of 30 ) parasites, and the other half had no eosinophilia with ( 3 of 30) or without (12 of 30) parasites. Of the 70.8\% with > 200 CD4 cells, $52 \%$ had eosinophilia with (48 of 90) or without (18 of 90) parasites, and $18.9 \%$ had no eosinophilia with (7 of 90 ) or without (17 of 90) parasites. In 5.5\% of the participants data on CD4 cell count and/or eosinophilia were not available. The median CD8+ count was 911.5 cells $/ \mathrm{mm}^{3}$, with a range between 51 to 3338 . Retrospective analysis of sera looking for predominant cytokine patterns was not feasible.

Of the stool samples provided by 133 individuals, $2 \%$ were hard, $65 \%$ formed, $22 \%$ soft, and $11 \%$ were diarrheic or liquid; in $1 \%$ this observation was not registered. No reference to acute or chronic diarrhea was made at the time of stool delivery by the participant, therefore we do not know what determined the consistency of the sample. Of the 15 diarrheic samples, 8 were negative for parasites and, in the remaining 7 very light infections of $A$. lumbricoides or T. trichiura were diagnosed. Ten percent (13 individuals) had Charcot-Leyden crystals in stools, alone (5 samples) or together with soil transmitted helminths (STH). Nine of the 13 cases were from San Pedro Sula. Incidental E. vermicularis adult worms were found in 2 $(1.5 \%)$ samples.

The specific parasite frequencies by cities of origin are shown in Table I. Sixty-seven percent of participants were infected with several species of pathogen and nonpathogen parasites. No cases of G. lamblia, acute amebiasis or cryptosporidiasis infections were diagnosed among the 133 participants. Frequencies were higher for Trichuris and Hookworm infections in San Pedro Sula, Tela, and La Ceiba, which are coastal areas, than in Tegucigalpa and Comayagua, which are located in the Central region, although no statistical differences were observed. Of the 5 Ascaris and 5 Trichuris infections with high egg count per gram of stool (epg) (range 11.44850.256 epg and 2160-9864 epg respectively), 3 ascariasis and 3 trichuriasis were registered from the coastal cities.

Thirty two percent of the cases (43/133) presented with mixed nematode infections. One participant was simultaneously infected with A. lumbricoides, T. trichiura, S. stercoralis, Taenia sp., and C. cayetanensis. The mean eosinophil percent for participants who were co-infected with soil-transmitted helminths was consistently and significantly higher than in those who were not infected with these types of parasites. The mean eosinophil percent was significantly higher $(\mathrm{p}<0.001)$ for Hookworm coinfected participants (22\%), compared to those who were not co-infected (7.2\%); the mean eosinophil percent for individuals infected with Trichuris was 11\% compared to $5.2 \%$ in those who were not co-infected ( $\mathrm{p}<0.001$ ), for $S$. stercoralis was $13.2 \%$ in co-infected compared to $7.5 \%$ in non co-infected ( $\mathrm{p}<0.05)$, and for A. lumbricoides, the mean eosinophil percent was $12 \%$ in co-infected vs $6 \%$ in non co-infected cases $(\mathrm{p}<0.05)$ (Table II). Table III shows the prevalence of non pathogen protozoa.

\section{DISCUSSION}

In epidemiologic studies aiming at detecting asymptomatic parasitic infections, some considerations include: 
TABLE II

Median of eosinophils and species of parasites in 133 human immunedeficiency virus positive infected participants

\begin{tabular}{lccc}
\hline $\begin{array}{l}\text { Parasite } \\
\text { species }\end{array}$ & \multicolumn{3}{c}{ Median of eosinophils } \\
\hline Hookworm & 22 & 7.2 & $<0.001$ \\
Trichuris & 11 & 5.2 & $<0.001$ \\
Ascaris & 12 & 6 & $<0.05$ \\
Strongyloides & 13.2 & 7.5 & $<0.05$ \\
\hline
\end{tabular}

species of parasites searched for, methods best suited and participant compliance. Under our conditions and facilities, it is difficult to obtain $100 \%$ participant compliance for repeated specimen delivery; therefore it was decided to obtain one stool sample and process it by different laboratory methods. Although examination of more than one sample may increase the number of parasites detected, the increase is modest and probably not significant for the overall results (Montessoni \& Bischoff 1987, Morris et al. 1992). Also, no one method is suited for diagnosis of all species of parasites; by processing and examining the samples by five different methods we expected to obtain acceptable, reliable results.

The results of this study indicate that the mean eosinophil percents for participants who were co-infected with soil-transmitted helminths was consistently and significantly higher than in those who were not infected with these types of parasites. These results are consistent with studies that show that infection with intestinal helminths results in immune responses involving cytokines produced by T-helper cell type 2, with IgE production, eosinophilia and mastocytosis (Bentwich et al. 1996, Kalinkowich et al. 1998, Bundy et al. 2000, Baum et al. 2003). In situations of chronic helminthic infections the Th2 subset dominates and is thought to depress Th-1 functions, facilitating HIV disease progression (Actor et al. 1993, Bentwich et al. 1996, Borkow et al. 2001, Baum et al. 2003). Th2 response has been associated with wasting and more rapid HIV disease progression, confirming previous research that showed that eosinophil percentages were directly and significantly correlated with viral load and inversely correlated with CD4 cell count (Actor et al. 1993, Bentwich et al. 1996, Kalinkowich et al. 1998, Borkow et al. 2001). As this study had been designed with other objectives in mind no follow up was considered; furthermore, the above mentioned correlations could neither be demonstrated or was it possible in retrospect to check for predominant cytokine patterns in the frozen sera. Observations in a recent study of Ethiopian Jews who recently migrated to Israel showing improvement and recovery of immune functions following de-worming, would be somewhat more difficult to prove in our case given that individuals continue living in contaminated environments (Bentwich et al. 1996, Borkow et al. 2001).

In this study, the participants were HIV positive, but not living with AIDS, individuals. They did not complain or report chronic diarrhea, although the stool consistency in $15(11 \%)$ individuals was diarrheic or liquid. The results of the parasitology exams reveal no specific trend in intestinal parasite occurrence in this group of HIV positive individuals and did not differ significantly from those found in other Honduran population groups (Kaminsky 1996). Intestinal helminths were present in $67 \%$ of the participants from all five locations, with higher percentages of frequency and intensity of infection of soil transmitted helminths in San Pedro Sula and Tela/La Ceiba, similar to previous observations (Kaminsky 1996). Most likely, the presence of infected individuals is clearly related to poor sanitation, use of contaminated water, utilization of common soil defecating areas, together with appropriate conditions of soil, temperature and humidity such as those prevailing at most locations in Honduras, which are ideal situations for the permanence of soil transmitted helminths (Beaver et al. 1985). Not finding C. parvum came as no surprise since in our local observations so far, it occurs mainly in children less than 5 years of age or in patients known to have some immunocompromise or AIDS (Kaminsky 2002). C. parvum was found infecting $12.5 \%$ of 80 AIDS patients in Tegucigalpa (Kaminsky 1998) and $25.3 \%$ of 79 AIDS patients in San Pedro Sula (personal observations) but not $21 \mathrm{HIV}$ positive nor 100 healthy commercial sex workers (Kaminsky 1999, 2000). Such observations are consistent with studies of AIDS patients from Central African Republic, Brazil, and Venezuela (Chacin-Bonilla et al. 1992, Costa Sauda et al. 1993, Germani et al. 1998).

Our results showed a high prevalence and a great variety of helminths as single or mixed infections. They suggest high human fecal contamination and frequent exposures. Because primary parasitic infections are generally associated with low mortality rate, control programs are

TABLE III

Frequency of non pathogen protozoa in human immunedeficiency virus positive participants in Honduras, by city of origin

\begin{tabular}{|c|c|c|c|c|c|c|c|}
\hline \multirow{2}{*}{\multicolumn{2}{|c|}{ City of procedence }} & \multicolumn{5}{|c|}{ Species of parasites } & \multirow{3}{*}{$\frac{B h}{15.2}$} \\
\hline & & \multirow{2}{*}{$\begin{array}{l}\text { Eha } \\
15.2\end{array}$} & \multirow{2}{*}{$\frac{E c}{15.2}$} & \multirow{2}{*}{$\frac{I b u}{6.5}$} & \multirow{2}{*}{$\begin{array}{c}E n \\
10.8\end{array}$} & \multirow{2}{*}{$\begin{array}{r}\text { Chm } \\
4.3\end{array}$} & \\
\hline Tegucigalpa & $\mathrm{n}=46$ & & & & & & \\
\hline Comavagua & $\mathrm{n}=29$ & 6.8 & 24.1 & 0 & 24.0 & 0 & 6.8 \\
\hline San Pedro Sula & $\mathrm{n}=38$ & 5.2 & 15.7 & 0 & 21.0 & 0 & 5.2 \\
\hline Tela/La Ceiba & $\mathrm{n}=20$ & 20 & 55.0 & 0 & 20.0 & 0 & 0 \\
\hline Totals & $\mathrm{n}=133$ & 11.2 & 23.3 & 2.2 & 18.0 & 1.5 & 8.2 \\
\hline
\end{tabular}

Eha: Entamoeba hartmanni; Ec: E. coli; Ibu: Iodamoeba buetschlii; En: Endolimax nana; Chm: Chilomastix mesnili; Bh: Blastocystis hominis 
usually given low priority. The newly emerging relationship of helminthic infections to HIV, however, and its potential impact on HIV progression, especially in countries where co-infection with HIV is a growing reality justify efforts for strengthening such programs, and increasing measures to prevent and remedy conditions that foster transmission of parasitic infections.

On the other hand, and from a practical point of view, it is interesting to realize that in the absence of a coproparasitological study, the finding of high eosinophil blood count should suggest to perform fecal examinations and, eventually, administer antihelminthic treatment.

\section{REFERENCES}

Actor I, Mursunori Sh, Kullberg M, Buller M, Sher A, Berzofsky J 1993. Helminth infection results in decreased virus-specific CD8+ cytotoxic T cell and Th1 cytokine responses as well as delayed virus clearance. Proc Nat Acad Sci USA 90: 948-952.

Alemán M, Sousa O 1991. Helmintiasis intestinales. Situación en Panamá. Rev Asoc Guatemalteca Parasit Med Trop 6: 29.

Ash L, Orihel TC 1987. Parasites: A Guide to Laboratory Procedures and Identification, ASCP Press, Chicago, p. 15-66.

Baum MK, Phillips JC, Sales S, Daniel V, Yang Z, Yang A, Campa A 2003. Eosinophilia is associated with HIV disease progression. Keystone Symposia in Alberta, Canada, March 29-April 4, Abstract 405.

Beaver PC, Jung R, Cupp E 1985. Clinical Parasitology, 9th ed., Lea \& Febiger, Philadelphia.

Bentwitz Z 1999. Can eradication of helmintic infections change the face of AIDS and tuberculosis? Immunol Today 20: 485-487.

Bentwich Z, Weisman Z, Moroz C, Bar-Yehuda S, Kalinkovich A 1996. Immune dysregulation in Ethiopian immigrants in Israel: relevance to helminth infections? Clin Exper Immunol 103: 239-243.

Borkow G, Weisman Z, Leng Q, Stein M, Kalinkovich A, Wolday D, Bentwich Z 2001. Helminths, human immunodeficiency virus and tuberculosis. Scand J Infect Dis 33: 568-571.

Botero D 1981. Persistencia de parasitosis intestinales endemicas en America Latina. Bol Of Sanit Panam 90: 39-47.

Bu Figueroa E, Fernández J, Alvarado T 1992. Características epidemiológicas y clínicas de los 100 primeros casos de SIDA en Honduras. Med Clín 1: 9-13.

Bundy DAP, Sher A, Michael E 2000. Good worms of bad worms: do worm infections affect the epidemiological patterns of other diseases? Parasitol Today 16: 273-274.

Chacin-Bonilla L, Guanipa N, Cano G, Raleigh X, Quijada L 1992. Cryptosporidiosis among patients with acquired immunodeficiency syndrome in Zulia State, Venezuela. Am J Trop Med Hyg 47: 582-586.

Costa Sauda F, Zamarioli LA, Ebner FW, Barros Mello L 1993. Prevalence of Cryptosporidium sp. and Isospora belli among AIDS patients attending Santos Reference Center for AIDS, São Paulo, Brazil. J Parasitol 79: 454-456.

Diamond L, Clark CG 1993. A redescription of Entamoeba histolytica Schaudinn, 1903 (emended Walker, 1911) separating it from Entamoeba dispar Brumpt, 1925. J Euk Microbiol 40: 340-344.

Evans E, Jamison D 1994. Economics and the argument for parasitic disease control. Science 264: 1866-1867.

Germani Y, Minssart P, Vohito M, Yassibanda S, Glaziou P, Hocquet D, Berthelemy P, Morvan J 1998. Etiologies of acute, persistent, and dysenteric diarrheas in adults in
Bangui, Central African Republic, in relation to Human Immunodeficiency Virus serostatus. Am J Trop Med Hyg 59: 1008-1014.

Guyatt H 2000. Do intestinal nematodes affect productivity in adults? Parasitol Today 16: 153-158.

Heyworth MF 1996. Parasitic diseases in immunocompromised hosts. Cryptosporidiosis, isosporiasis and strongyloidiasis. Gastroent Clin North Am 25: 691-707.

INDRE-Instituto Nacional de Diagnóstico y Referencia Epidemiológicos 1994. Encuestas Centinelas para la Evaluación de la Eficacia de la Quimioterapia Masiva Contra Helmintos Intestinales, Octubre 1993, Instituto Nacional de Diagnóstico y Referencia Epidemiológicos. Subsecretaría de Coordinación y Desarrollo, México.

Kalinkowich A, Weisman Z, Greenberg Z, Nahmias J, Etian S, Stein M, Bentwich R 1998. Decreased CD4 and decreased CD8 counts with T-cell activation is associated with chronic helminth infection. Clin Exp Immunol 114: 414-421.

Kaminsky RG 1996. El Parasitismo en Honduras. Serie de Diagnósticos No. 14, Organización de la Salud/Organización Mundial de la Salud, Honduras.

Kaminsky RG 1999. Parásitos intestinales en diferentes poblaciones de Honduras. III. Prevalencia de parásitos intestinales en pacientes VIH/SIDA. Rev Méd Hondureña 67: 235-242.

Kaminsky RG 2000. Parásitos intestinales en diferentes poblaciones de Honduras. IV. Trabajadoras comerciales del sexo. Rev Méd Hondureña 68: 134-140.

Kaminsky RG 2002. Comparación epidemiológica entre apicomplexa intestinales en población hospitalaria en Honduras. Rev Méd Hondureña 70: 164-172.

Loufty M, Wilson M, Keystone J, Kain K 2002. Serology and eosinophil count in the diagnosis and management of strongyloidiasis in a non-endemic area. Am J Trop Med Hyg 66: 749-752.

Montessoni G, Bischoff L 1987. Searching for parasites in stool: once is usually enough. Can Med Assoc J 137: 702.

Morris AJ, Wilson ML, Reller LB 1992. Application of rejection criteria for stool ovum and parasite examinations. J Clin Microbiol 30: 3213-3216.

Nokes C, Grantham-McGregor SM, Sawyer AW, Cooper ES, Robinson BA, Bundy DAP 1992. Moderate to heavy infections of Trichuris trichiura affect cognitive function in Jamaican school children. Parasitology 104: 539-547.

Porto AF, Neva F, Bittencourt H, Lisboa W, Thompson R, Alcantara G, Carvalho E 2001. HTLV-1 decreases Th2 type of immune response in patients with strongyloidiasis. Parasite Immunol 23: 503-507.

Renjifo B, Blackard J, Klaskala W, Chaplin B, Shah P, McLane M, Barin F, Esparza J, Zelaya J, Osmanov S, Soto R, Fernández J, Baum M, Essex M 1999. HIV-1 subtype B in Honduras. Virus Res 60: 191-197.

Savioli L, Stansfield S, Bundy DAP, Mitchell A, Bhatia R, Engels D, Montresor A, Neira M, Shein AM 2002. Schistosomiasis and soil transmitted helminthic infections: forgoing control efforts. Trans $R$ Soc Trop Med Hyg 96: 577-579.

Sosa C, Klaskala W, Chandran B, Soto R, Sieczkowski L, Wu HM, Baum M, Wood C 1998. Human herpesvirus 8 as a potential sexually transmitted agent in Honduras. $J$ Infect Dis 178: 547-551.

Soto RJ 1998. La epidemia de VIH/SIDA en Latinoamérica: desafíos y respuestas. La situación de Honduras. I Conferencia de Cooperación Técnica Horizontal. Querétaro, México.

Soto RJ, Alvarenga M, Walker N, Garcia-Calleja JM, Zacarias 
F 2002. Estimating HIV/AIDS prevalence in countries with low-level and concentrated epidemics: The example of Honduras. AIDS 16 (Suppl. 3): s18-s22.

Volmer TL, Waldor MK, Steinman L Conley FK 1987. Depletion of T-4+ lymphocytes with monoclonal antibody reactivates toxoplasmosis in the central nervous system: a model of superinfection in AIDS. J Immunol 138: 3737-3741.
Wheeler D, Arathoon EG, Pitts M, Cedillos R, Bu TE, Porras GD, Herrera G, Sosa NR 2001. Availability of HIV care in Central America. J Am Med Assoc 286: 853-60.

WHO-World Health Organization 1994. Bench Aids for the Diagnosis of Intestinal Parasites, Programme on Intestinal Parasitic Infections, Division of Communicable Diseases, Geneva. 